NBER WORKING PAPER SERIES

FACTOR MARKET BARRIERS ARE TRADE BARRIERS:
GAINS FROM TRADE IN 1992

Richard Baldwin

Working Paper No. 2656

NATIONAL BUREAU OF ECONOMIC RESEARCH

1050 Massachusetts Avenue

Cambridge, MA 02138

July 1988

I gratefully acknowledge the helpful comments and suggestions of Alberto Giovannini, Jagdish Bhagwati, Rich Lyons, Ron Findlay, Aaron Torne11, Paul Krugman and Mike Gavin. This research is part of NBER's research program in International studies. Any opinions expressed are those of the author not those of the National Bureau of Economic Research. 
NBER Working Paper \#2656

July 1988

\section{FACTOR MARKET BARRIERS ARE TRADE BARRIERS: \\ GAINS FROM TRADE IN 1992}

\section{ABSTRACT}

The European Community's economic integration by 1992 is predicted to have large economic benefits. According to traditional trade theory, the gains will come only with permanent resource migration and significant factor price changes (since in principle all trade barriers have already been removed). Yet, it seems unlikely that the 1992 reforms will be completed, if they do indeed result in factor movements large enough to substantially alter factor rewards.

This paper presents a more optimistic view. It argues that factor market integration can result in economic gains, even without capital and labor migration. The basic argument is simple. For some types of goods, it is cheaper to conduct trade on an intra-firm basis, rather than an inter-firm basis (for instance roughly half of US imports are intra-firm, Helleiner [1981]). In such industries, any factor market barrier that raises the cost of foreign control of local firms also raises the cost of intra-firm trade. Consequently, removing such barriers can lead to gains from trade. The 1.O. trade literature points out that intra-firm trade requires direct foreign control which need not involve direct foreign investment (Helpman and Krugman [1385]). Therefore, 1992 can logically lead to gains from additional intra-firm trade, with little additional capital or labor migration. 


\section{Introduction}

The approach of 1992, the target date for the European Community's much touted economic integration, has elicited a number of rather extravagant claims on the part of pan-Europeanists concerning the benefits of a single European market. The move, they assert, will result in higher productivity, more efficient allocation of resources, higher living standards and enhanced export competitiveness.

In the context of traditional trade theory, these claims appear exaggerated. In principle, all trade barriers have already been removed between the European Community (EC) nations, and factor prices are already approximately equal - at least among the otiginal six member countries. With no tarifís and equal factor prices, the Hecksncer-Ônin model predicts that factor market liberalization should have no effect. Indeed this is one of the principle lessons of the model. Trade in goods is a substitute for trade in factors.

Recognizing, however, that there are wage differences within the newly expanded EC, we should expect efficiency gains from the 1992 program. Yet according to traditional trade theory (as extended by the Mundell-Jones factor mobility model), these gains will come only with rather massive, and permanent, labor migration from the low wage "southern" members, and capital outflow from the "northern" members. Moreover, if the liberalization is to lead firms to choose a more efficient international allocation of resources, it must necessarily alter factor prices.

While such international resource migration would undoubtedly result in the predicted economic benefits, it seems unlikely that this is what policy makers have in mind. Indeed it is doubtful that the reforms would be completed if they result in factor movements iarge enough to significantly alter factor rewards. Thus an analyst using the traditional framework should be rather pessimistic about the outcome of the 1992 program. In that framework, economic gains come only with politically difficult factor migration,

This paper presents a more optimistic view. It argues that factor market integration can result in the economic gains discussed above, even without capital and labor migration. The basic argument is simple. For some types of goods, international vertical integratation is 
essential to efficient international trade. That is to say, for such goods it is cheaper to conduct trade on an intra-firm basis, rather than an inter-firm basis. In such industries, those factor market barriers which raise the cost of foreign control of local assets have the effect of raising the cost of trade. Consequently, removing such barriers can lead to gains from trade. The industrial organization literature stresses that the key aspect of vertical integration is control, not investment. Therefore, while the removal of such barriers may increase international vertical integration, it need not involve international capital mobility (see for instance Helpman and Krugman [1985]).

As noted by Bhagwati [1982], the point that barriers to capital mobility may act as non-tariff barriers arose in the debate over "invisible" Japanese trade barriers. While Bhagwati [1982] is skeptical of the validity of this contention, he examines the welfare effects of freer capital mobility when capital mobility reduces implicit protection. In particular he demonstrates that this aspect of capital flows implies that a country can gain from capital exports (even when they are by themselves directly unprofitable) due to the welfare gain from freer trade in goods engendered by the capital exports.

The present paper differs from Bhagwati [1982] in three respects. We focus on international vertical control rather than limiting ourselves to foreign direct investment. We explicitly model the manner in which factor market barriers are barriers to trade. Lastly, our analysis is done in the context of an intra-industry trade model (Krugman [1979]), rather than the standard factor abundance trade model as in Bhagwati.

The rest of the paper is divided into five parts. The second section examines the general proposition that some factor market barriers are barriers to trade. Section three lays out an explicit, single firm example to formalize the symmetry between trade barriers and factor market barriers. The next section presents a simple general equilibrium trade model and derives the equilibrium with factor market barriers. The fourth section studies the comparative statics of removing the factor market barriers. The last section contains a summary and concluding remarks. 


\section{Some Factor Market Barriers Act as Barriers to Trade}

In this section we consider a general model of a domestic firm which exports a product to a foreign country. We assume that manufacture of the good is concentrated in the home country (due, for example, to factor prices difference, technology differences, or economy of scales). Sale of the good to foreign consumers requires more than just physical manufacture. We assume that in order to sell the product, additional services must be provided. These services are intended to represent "support" or "consumer" services such as maintenence and repair services, as well as marketing and distribution costs. As such, we assume that the provision of these services must take place in the foreign country. We refer to these services as downstream services. This necessity of downstream services limits the types of goods to which our argument applies.

We assume that the firm has the option of organizing its exports via international vertical integration or arm's-length trading. In the first case the home firm which manufactures the good is unrelated to the foreign firm which provides the downstream services. In the second, the two firms are under a common direction (here we arbitrarily assume that it is the home firm that controls the foreign). The first case is inter-firm trade, the second is intra-firm trade.

Next we address the nature of the factor market barriers which may act as trade barriers. Virtually all industrial economies have a multitude of barriers to factor market integration. The employment of foreign managers and skilled workers (even by foreign firms) is typically subject to a plethora of red-tape requirements, bureaucrat ic delays and/or taxation (if not outright prohibition). If these workers are important to the efficient control and operation of foreign affiliates, then such labor market barriers raise the cost of exporting. Similarly, the control and ownership of assets by foreign companies usually faces a whole array of restrictions and costly regulations.

International differences in laws concerning patents, licensing, franchising and other forms of vertical constraint can similarly inhibit international vertical integration. Also in 
this category of barriers to trade-related MNC activity are national anti-trust, and merger and acquisition policies which discriminate against foreigners.

There are probably interesting insights to be gained from explicitly modeling the manner in which each of these barriers raises the costs of foreign control of local firms.

However to make our general point as clearly as possible, we simply assume that the net effect of these barriers is to raise the cost of providing the downstream services when the local firm is controlled by a foreign firm. In particular, we consider two categories of these cost raising barriers: those which raise the marginal cost of providing downstream services when the foreign firm is controlled by a home firm, and those which raise the fixed cost of controlling a foreign firm from the home country.

We presume that vertical integration occurs when the sum of profits of the two firms operating independently, $\Pi^{\mathrm{al}}$, is less than the sum of profits when the firms are under a common direction, $\Pi^{\mathrm{vi}}$. We can write this as the vertical integration contraint:

$$
\begin{gathered}
\Pi^{\mathrm{vi}}>\Pi^{\mathrm{al}}, \text { where } \\
\Pi^{\mathrm{vi}}=\underset{x, y}{\operatorname{argmax}}\left[\pi^{M}[x]+\pi^{D}[y]\right], \text { s.t. } y=f(x, z) \\
\Pi^{\mathrm{al}}=\underset{\mathbf{x}}{\operatorname{argmax}}\left[\pi^{M}[x]\right]+\underset{y}{\operatorname{argmax}}\left[\pi^{D}[y]\right], \text { s.t. } y=f(x, z)
\end{gathered}
$$

where $\pi^{\mathrm{M}}$ and $\pi^{\mathrm{D}}$ are the profits of the manufacturer and downstream firms, $\mathrm{x}$ and $\mathrm{y}$ are the choice variables of the two firms, and $f$ is the production function describing the transformation of the manufactured good into a saleable final good ( $\mathrm{z}$ represents all other inputs).

The next section presents an explicit model in which (1) holds due to the well known $\mathrm{K}-\mathrm{C}-\mathrm{A}$ quasi-rent motive for vertical integration. Any one of many other vertical integration motives could have been used. Blair and Kaserman [1383] describe five basic vertical integration motives: $\mathrm{K}-\mathrm{C}-\mathrm{A}$ 's quasi-rent, incomplete contracts, sequential market power, implicit insurance and transaction costs. 
We are now ready to consider the two categories of barriers. Given that the vertical integration constraint holds, the total cost of selling to the foreign country is:

$$
C[y]=(c[y]+F)+\left(c^{*}[y](1+\beta)+F^{*}(1+\lambda)\right)
$$

where $\beta$ and $\lambda$ represent the cost-raising effect of the first and second category of barriers, $c[y], c^{*}[y], F$ and $F^{*}$ are the cost functions and fixed costs associated with manufacturing and the downstream services respectively.

We turn first to the barriers represented by $\beta . \beta$ raises the marginal cost of exporting. This follows from differentiation of (2) with respect to $\mathrm{y}$. $\beta$ will therefore reduce trade in any model where the firm's sales are decreasing in marginal costs. This is a property of sales in modeis employing a broad class of technologies and market structures (the section three model provides an example). In such models, the barriers reduce the volume of trade by increasing the marginal cost of trade.

Barriers which raise the fixed cost of controlling a home firm from abroad are also trade barriers, assuming only that the market structure is such that price of the final good is positively related to average costs. For example allowing free entry and ignoring the integer constraint, we have that price equals average cost, in equilibrium. Since this category of barriers raises average costs, it raises prices and so leads to less trade.

\section{A. Caveats and Discussion}

The main result depends crucially on three points: (i) downstream services must be located in the foreign country, (ii) the vertical integration constraint must hold, and (iii) the factor market barriers must raise the cost of providing the downstream service.

The first caveat that should be mentioned is that the result can only be expected to hold for certain types of goods. For many types of goods, the marketing and distribution can be efficiently performed by firms that are unrelated to the manufacturer. Inexpensive apparel, processed foods and certain consumer electronics are some examples of such goods. For these types of goods the barriers inhibit MNCs but do not inhibit trade since the 
downstream service can be efficiently provided by locally owned firms which is not subject to the barrier.

Also for some types of products, there is no need to provide downstream services. Again, for such products the symmetry of factor market barriers and trade barriers would breakdown. Since in these industries $\mathrm{MNC}$ activity is not essential to trade, barriers to MNCs need not affect trade.

We assumed that the factor market barriers could be translated into a cost raising effect. Absolute quantitative restrictions would probably lead to similar results but more complicated analytics. In the case of the Leontief relationship between manufacturing and downstream services, a quantitative restriction on foreign ownership of downstream assets implies a quantitative restriction on imports. In which case they obviously constitute barriers to trade. Nonetheless, in general the effects of quantative restriction on trade are quite sensitive to assumptions on market structure and strategic choice variables (Krishna [1985]).

It is conceivable that a high enough $\beta$ or $\lambda$ would make arm's-length trading less costly than vertical integration. For such high levels of $\beta$ or $\lambda$, the downstream servives would be provided by unrelated, local firms. Small changes in $\beta$ and $\lambda$ would therefore not affect trade. What this argues is that since vertical integration is only one possible organizational form, there is an upper bound to the trade-inhibiting effects of $\beta$ and $\lambda$. Nonetheless, complete remoral of $\beta$ and $\lambda$ would have the trade effects similar to those of tariff reductions.

\section{An Explicit Single Firm Example}

The model we employ combines elements of the headquarter services model of MNCs (Helpman and Krugman [1985]) and the beachhead or sunk cost model (Baldwin [1986]). A number of highly special assumptions are made in order to focus attention on the essential economics of the problem.

Consider a firm producing a differentiated product for sale to two identical countries. 
Physical manufacture of the good is subject to increasing returns and so is concentrated in one country (which we call the home country without loss of generality). The economies of scale take the form of the standard fixed-cost-plus-constant-marginal-cost variety. Production of the final good, however, requires more than just physical manufacture. We assume that in order to sell the product to either market, the firm must also incur additional costs. These costs represent the downstream services discussed in the previous section.

To provide these downstream services, the firm must control assets that are completely distinct from those involved in physical manufacturing. We make two important assumptions on the nature of these downstream assets. First, due to the differentiated nature of the good, the downstream assets are firm-specific. In other words the physical and human capital necessary to provide the services is particular to the good and is therefore sunk. Second, since the assets are aimed at providing services to consumers, they must be located in the same country as the consumers. Thus the firm must aquire these assets in both the home and foreign country if it wishes to sell to both markets. Photocopiers, farm machinery and automobiles are some examples of products that require in-country servicing and distribution facilities.

To keep things simple, we assume that production of the final good requires a fixed coeficient combination of manufacturing and downst ream services. Lastly, we assume that the provision of the consumer services is subject to constant returns.

\section{A. Vertical Integration Motive}

As has been stressed in the 1 .O. trade literature, any model of $\mathrm{MNC}$ activity must answer two questions: 1) Why does production of the final good involve assets in more than one country? and 2) Why are the assets (which are located in different countries) owned by the same firm instead of by two unrelated firms?

In this model the nature of the product answers the first question. The production of the final good requires two types of assets: those involved in the provision of consumer services, and those involved in physical manufacturing. Due to scale economies in manufacturing, assets are located in a only one country. Due to the nature of consumer 
services, distribution and repair facilities must be located in both countries.

The answer to the second question comes from the nature of the assets. In particular it is due to the specificity of the downstream assets. As Klein, Crawford and Alehian [1982] originally showed, the specificity of assets creates quasi-rents. Quasi-rents imply that arm's-length trade in the manufactured good and the downstream service is an organizational form that is inferior (i.e., more costly) to vertical integratation. Helpman and Krugman [1985] apply the Klein-Crawford-Alchian (K-C-A) logic to explain the vertical integratation of internationally disperse assets, i.e., the existence of MNCs.

The basic $\mathrm{K}-\mathrm{C}-\mathrm{A}$ idea is quite simple. The specificity of the assets implies that they are sunk. Once they are sunk, they create rent $(\mathrm{K}-\mathrm{C}-\mathrm{A}$ call this quasi-rent since it is only rent ex post, not ex ante). Dispute over the division of this rent and strategies undertaken in anticipation of this dispute lead to inefficencies which can be aroided by internalizing the rent-division problem. Of course vertical integration need not occur if one is willing to make the extreme assumption that the firms can costlessly write complete and credible contracts. We suppose that such contracts are not available.

Next we turn to the factor market barriers. As in the previous section, we assume that the net affect of these barriers is to raise the home firm's cost of providing the downstream services in the foreign market. Moreover, we assume that the barriers raise the marginal costs of doing so. Thus the marginal cost of providing the downstream services is $d$ in the home country and $d(1+\beta)$ in the foreign country (since in the foreign country the assets are controlled by the home firm). We interprete $\beta$ as the shadow price of factor market barriers.

In most industrialized countries, factor market barriers are not intended to raise government revenue. To model this we assume that the $\beta$ represents "frictional" barriers. That is to say, the barriers do nothing but raise the cost of foreign control of local assets. Assuming that $\beta$ results in some government revenue would not alter any of the results in this partial equilibrium analysis.

\section{B. Some Barriens to Factor Market Integration Trade Barriers}

We are now ready to examine the problem of the firm and derive our main result. The 
firm has a monopoly in the market for its own differentiated product. To facilitate the comparison of factor market barriers and standard trade barriers, we assume that the value of exports (when it crosses the border) is subject to an ad valorum tariff of $\tau$ percent. Thus the marginal cost of exporting must include the tariff. The firm chooses domestic price and export price subject to demand functions in order to maximize profits. Thus:

$$
\underset{p, p^{*}}{\max } p+p^{*} x^{*}-c x+c(1+\tau) x^{*}-d x-d(1+\beta) x^{*}-F
$$

where $F$ is the fixed cost of manufact uring, $c$ is the marginal cost of manufacturing, $x$ is domestic sales and $x^{*}$ is export sales. The first order conditions (we assume that the demand functions are such that interior solutions occur) are:

$$
\begin{gathered}
p x^{\prime}[p]+x=(c+d) x^{\prime}[p] \\
p^{*} x^{\prime}\left[p{ }^{*}\right]+x^{*}=[c(1+\tau)+d(1+\beta)] x^{\prime}\left[p^{*}\right]
\end{gathered}
$$

These equations together with the two identical demand functions determine the trade volume and price as well as home sales and price. Simply re-arranging the first order conditions we get:

$$
\begin{gathered}
\mathrm{p}=\left(\frac{1}{1-1 / \epsilon(\mathrm{x})}\right)(\mathrm{c}+\mathrm{d}) \\
\mathrm{p}^{*}=\left(\frac{1}{1-1 / \epsilon\left(\mathrm{x}^{*}\right)}\right)(\mathrm{c}(1+\tau)+\mathrm{d}(1+\beta))
\end{gathered}
$$

where we allow the demand elasticities, $\epsilon$ and $\epsilon^{*}$, to be a function of the level of sales. Sales are simply: 


$$
\begin{gathered}
x=x\left[\left(\frac{1}{1-1 / \epsilon(x)}\right)(c+d)\right] \\
x^{*}=x\left[\left(\frac{1}{1-1 / \epsilon\left(x^{*}\right)}\right)(c(1+\tau)+d(1+\beta))\right]
\end{gathered}
$$

Equations (5b) and (6b) demonstrate our main result. The shadow price of factor market barriers affect trade in the same way tariffs do. That is to say, in this model factor market barriers act as trade barriers. In particular $\tau$ and $\beta$ both affect the marginal cost of exporting. Of course, $\tau$ falls only on the value of the product that crosses the border, while $\beta$ falls only on the value added in-country. As a result, increases in $\tau$ and $\beta$ will have identical trade effects only if $c=d$. This can be seen by inspection of (5b) and (6b).

To reiterate, when MNC activity is essential to international trade, barriers to the MNC activity constitute barriers to trade.

\section{A Two Country-Two Industry Model}

The model combines elements of the model in the previous section with the Krugman [1980] model of trade. Specifically we consider two identical countries which have no explicit trade barriers between them but which do have factor market barriers of the type discussed in the previous section.

Again to streamline the algebra, we make a number of highly special assumptions. We suppose that labor is the only fixed factor of production and there are only two industries. The first (the $x$ sector) consists of Spence-Dixit-Stiglitz differentiated products. ${ }^{2}$ These goods are produced according to the technology outlined in the previous section, namely increasing returns in physical production and constant returns in downstream services. The market structure is assumed to be Chamberlain monopolistic competition with price as the strategic variable. The other industry produces a homogeneous good (referred to as A) subject to constant return to scale and perfect competition. We employ the convenient fiction 
of a representative consumer (in each country) who is endowed with $L / 2$ units of labor.

Tastes in each country are defined by the utility function:

$$
U=\left(\left(\underset{i \in \Omega}{\Sigma_{i}} x^{\theta}\right)^{1 / \theta}\right)_{(A)}^{(1-\alpha)}
$$

where $\Omega$ is the set of $x$ varieties produced. Taking the labor as the numeraire, the world demand functions arising from utility maximization in both countries are:

$$
A=p_{a}^{-1}(1-\alpha) L
$$

and

$$
x_{i}=\frac{p_{i}^{-\theta}}{\sum_{i \in \Omega} p_{i}^{1-\theta}} \alpha L \text {, for a typical home variet } y \text {, }
$$

and

$$
\mathrm{x}_{\mathrm{k}}^{*}=\frac{\mathrm{p}_{\mathrm{k}}^{*}-\theta}{\sum_{\mathrm{i} \Omega} \mathrm{p}_{\mathrm{i}}^{1-\theta}} \alpha \mathrm{L} \text {, for a typical imported variety, }
$$

where $\Omega$ is the set of varieties that are actually produced.

The elasticity of demand for a single variety of $x$ is an important parameter in the model. With each monopolistic competitor taking all other prices as given, the exact demand elasticity for variety $k$ with respect to its price is:

$$
\epsilon=\theta+(1-\theta)\left(\frac{\mathrm{p}_{\mathbf{k}}^{1-\theta}}{\sum_{i \in \Omega} \mathrm{p}_{\mathrm{i}}^{1-\theta}}\right)
$$

In a symmetric equilibrium this is $\theta+\frac{1-\theta}{m}$, where $m$ is the total number of varieties sold. Following Helpman and Krugman [1985], we assume that there are many varieties so firms ignore the second term and act as if $\epsilon=\theta$. 


\section{A. The "A" Industry}

Production of a unit of the A good requires " $a$ " units of labor in physical manufacture. Additionally it requires downstream services that involve " $b$ " units of labor if the downstream services are provided by locally owned firms, and $b(1+\beta)$ units of labor if they are provided by a firm that is controlled from abroad. As in the previous section, $\beta$ is the shadow price of the frictional regulations and restrictions on international control of human and physical assets.

Since the A good is a homogeneous product, there is no rent-division problem to motivate vertical integration. That is, since the downstream assets can service any $\mathrm{A}$ manufacturer's output, the owners are not open to ex post exploitation by any single manufacturer.

Given this technology, perfect competition implies that there is no MNC actipity in the $A$ good (so the downstream services are provided by local firms that are unrelated to the manufactures) and its price is:

$$
p_{a}=a+b
$$

Given (11), the demand function implies world output of $\mathrm{A}$ is $(1-\alpha) \mathrm{L} /(\mathrm{a}+\mathrm{b})$. Consequently $(1-\alpha)$ t units of the world labor endowment are employed in the production of A. Given the symmetry of the two countries, there need be no trade in $\mathbf{A}$.

\section{B. The $x$ Industry}

The problem of a typical firm in industry $\mathrm{x}$ is similar to the one described in the previous section. It chooses domestic and export prices to maximize profits, and thus its first order conditions are identical to $(4 \mathrm{a})$ and $(4 \mathrm{~b})$, with $\tau=0$. That is, the price of each imported variety of $\mathbf{x}$ is given by (4b). The price of each domestically produced variety is given by (4a). Using the demand functions, local and export sales (for both home and foreign firms) are respectively: 


$$
x_{i}=(1 / n)\left(\frac{1}{1+(1+\phi)^{1-\theta}}\right)\left(\frac{1-1 / \epsilon}{c+d}\right) \alpha L \text {, }
$$

and

$$
\mathrm{x}_{\mathrm{i}}^{*}=(1 / \mathrm{n})\left(\frac{1}{\left(\frac{1}{1+\phi}\right)^{1-\theta}+1}\right)\left(\frac{1-1 / \epsilon}{\mathrm{c}+\mathrm{d}(1+\beta)}\right) \alpha \mathrm{L}
$$

where $1+\phi=\left(\frac{c+d(1+\beta)}{c+d}\right)$, so that $\phi$ is the percent by which the factor market barriers increase the marginal cost of export versus local sales. By symmetry (10a) and (10b) describe the domestic and export sales of a typical firm in each country.

To close the model we must determine the equilibrium number of varieties of $x$ produced in each country, $n$. Assuming free entry into the $\mathbf{x}$ industry and ignoring the integer constraint, firms in each country enter up to the point where profits are zero. To calculate the level of profits leaving out fixed costs, we rewrite (4a) and (4b) as, $p(1-1 / \epsilon)=(c+d)$, $\mathrm{p}(1-1 / \epsilon)=(\mathrm{c}+\mathrm{d})(1+\phi)$. Adding and rearranging these equations, we get:

$$
[p-(c+d)] x+\left[p^{*}-(c+d)(1+\phi)\right] x=(1 / \epsilon)\left(p x+p^{*} x^{*}\right)
$$

This shows that at the maximium, operating profits are a fraction of revenue (the fraction depends only on the perceived demand elasticity). Given the symmetry of all $x$ firms, it must be that the revenue of a typical $x$ firm is one $2 n-t h$ (where $n$ is the number of firms) of the world wide expenditure on $x$. World expenditure is on $x$ is $\alpha E$ in this model, so $F=(1 / \epsilon)(\alpha \tau / 2 n)$. Clearly then $n$ is given by :

$$
\mathrm{n}=(1 / \epsilon) \frac{\alpha \Phi}{2 F}
$$

To be certain that the model is closed by (13), we must address the issue of the possibility of revenue associated with the factor market barriers. Here our assumption that $\beta$ represents "frictional" regulations and restrictions (and thus does not give rise to any government revenue) becomes important. If $\beta$ did lead to government revenue, all results would go through as long as the revenue was returned in a lump-sum fashion to consumers. 
Walras' law implies that total world labor demand equals $I$.

\section{Description of the Equilibriurn}

In summary we have Krugman-type intra-industry trade in the $\mathrm{x}$ industry, but no trade in A. By symmetry, trade is balanced and the imports of each country are nx * Total domestic sales of $x$ by local firms is $n x$. Simple manipulation of $(5 a),(5 b),(6 a)$ and (6b) implies that the domestic share of total $x$ industry sales in each country is equal to:

$$
\sigma \equiv\left(\frac{n p x}{n p x+n p x}\right)=\left(\frac{1}{1+(1+\phi)^{1-\theta}}\right) .
$$

Note that this share is greater than $1 / 2$ and increasing in $\phi$ (and thus $\beta$ ) since $\theta>1$. A convenient measure of import penetration is simply $(1-\sigma)$.

In addition to intra-industry trade, there is two-way MNC activity in the same industry. In other words there is intra-industry foreign direct investment (IIFDI) in the $x$ industry. Given the Leontief combination of manufacturing and downstream services in the $x$ industry, the share of downstream firms controlled by foreign firms is also given by $(1-\sigma)$.

In this model we can be completely agnostic about the issue of the international mobility of factors. The symmetry and lack of trade barriers implies that $\mathrm{MNC}$ activity need not involve the physical movement of labor. Our vertical integration motive merely requires that the manufacturing and downstream service assets be controlled by a single firm.

To focus as sharply as possible on the difference between this model and the Mundell-Jones model, we make an extreme assumption. We assume that (as in the Helpman-Krugman [1985] headquarter services MNC model) foreign control of local assets is possible without any physical migration of labor. In other words, MNC activity involves only direct foreign control, not investment. Nonetheless, we could have assumed that some migration of labor is necessary to MNC activity without changing any of the analytics or results. All such migration would be two-way migration. That is, there would be no net migration. 


\section{The Comparative Statics of Removing Factor Market Barriers}

Given the equilibrium conditions derived in the previous section, it is easy to study the comparative statics of removing the factor market barriers. The key is to note that if $\beta=0$ then $\phi=0$, and the model becomes completely symmetric. In the $x$ sector, the domestic and export prices become the same. Nothing changes in the A sector since nothing depended on $\beta$ in that sector.

In general, the complete removal of discriminatory government policies need not imply that $\beta$ equals zero. Foreign control of local assets may be more expensive than local control due to differences in language, culture and social institutions. However, to simplify the analytics we study the comparative static effects of changing $\beta$ from a positive number to zero. It is important to note that what we are comparing are two equilibria, not the move from one equilibrium to another. The presence of beachhead-type sunk costs implies hysteresis in trade (Baldwin [1986]). Thus removing $\beta$ may have effects that differ from those predicted by comparative statics (more on this in the conclusion).

\section{A. Positive Effects}

To evaluate the positive effects of factor market liberalization, we examine the equilibrium condition in section III for $\phi=0$. Ey inspection of equations (8) and (11), there is no change in the output, price or trade pattern of $A$. There are, however, many changes in the $x$ industry. These are:
1) the export price of $x, p^{*}$, falls,
2) the domestic price of $x, p$, is unchanged,
3) there is no change in the equilibrium number of firms, $n$.

Points 1, 2 and 3 can be seen by inspection of (5a), (5b), (6a), (6b) and (13). Also,

4) the volume ( $n x^{*}$ ) of exports (which equals imports by symmetry) rises,

5) the volume of local $x$ sales by domestic firms $(n x)$ falls.

Equations (2a) and (2b) together with point 3 abore, imply points 4 and 5. Also,

6 ) our measure of import penetration $(1-\sigma)$ rises to $1 / 2$, 
7) the value of exports $\left(\mathrm{np}^{*} \mathrm{x}^{*}\right)$ rises.

Point 6 is obvious in equation (14). To see point 7 , we multiply equation (9b) by $\mathrm{p}^{*}$, and use (5b) to get: $\mathrm{p}^{*} \mathrm{x}^{*}=\left(\alpha[/ \mathrm{n})\left(1+(1+\phi)^{\theta-1}\right)^{-1}\right.$. Inspection of this expression demonstrates point 7. Next,

8) total output per firm $\left(x+x^{*}\right)$ rises,

9) measured labor productivity (output per worker) rises.

Point 8 is easy to show. Recall that optimal revenue is $1 / \mathrm{E}$ times operating profits. With free entry, operating profits must equal F. Thus rearranging the zero-profit condition produces: $\mathrm{F}=\mathrm{F} / \epsilon-(\mathrm{c}+\mathrm{d})\left(\mathbf{x}+\mathrm{x}^{*}(1+\phi)\right)$. Clearly then the typical firm's total output must be higher when $\phi=0$ than when $\phi>0$. Point 9 follows directly from point 8 together with the fixed cost nature of the scale economies.

Next we examine the effects that setting $\phi=0$ has on factor migration and MNC activity. Here there are $t$ wo basic points:

10) the liberalization need not involve labor migration, and

11) the degree of two-way MNC activity increases.

The tenth point is obvious from the symmetry of the two countries and our assumption that control need involve no labor movement. The eleventh point follows directly from point 6 . If $(1-\sigma)$ of all local sales are made by foreign firms, then $(1-\sigma)$ of the downstream service facilities must be controlled by foreigners (recall $1-\sigma=1 / 2$ with $\phi=0$, but is less than $1 / 2$ with $\phi>0)$.

Points $1-9$ state that the 1992 program could logicalip increase productivity, export performance, and allow greater economies of scale without causing any factor migration.

\section{B. Welfare Effects}

The major result of section II is that a factor market barrier, $\beta$, acts like a trade barrier. In general, the welfare effect of removing trade barriers is ambiguous. Consumers benefit through lower prices. However, due to Brander and Spencer [1981] reasoning, the loss in profits to domestic firms may more than outweigh the gains to consumers. Moreover, in general the liberalization may entail the exit of some firms, reducing the number of varieties 
available. In this paper, however, we have made assumptions that have the effect of removing these ambiguities.

Specifically, our assumption of free entry and abstraction from the integer constraint remores the possibility of rents. The choice of the Cobb-Douglas upper-tier utility function and constant perceived elasticity implies that the total number of available varieties is unaffected by the liberalization. Consequently, in this paper mutual remoral of factor market barriers improves welfare in both countries. Furthermore, it does so without any factor migration. This statement follows from the fact that removing $\beta$ does not change the output of $\mathrm{A}$ nor the number of varieties but does result in higher $\mathbf{x}$ industry output (point 8 ). Clearly then the utility of the representative consumer in each county is increased.

\section{Summary and Concluding Remarts}

The principle result of this paper is that for some $t y$ pes of products, barriers to foreign control of local facilities represent barriers to trade. Consequently, removal of factor market barriers which boost the cost of foreign control of home firms can result in gains from trade: higher productivity, more efficient allocation of resources, higher living standards and enhanced export competitiveness. At least in principle, these gains can be realized without any factor migration.

The results in this paper raise two additional interesting issues. First is the issue of how large the effects are likely to be in practice. While this sort of empirical work is crucial, it is unlikely to be straightforward. Non-marginal changes together with imperfect competition and economies of scale, make empirical work difficult. The computable general equilibrium modelling (see Harris and Cox [1982]) methodology would appear to be the most promising approach.

The second issue is that of dynamics. Comparative statics provides a reasonable guess as to where the liberalization will eventually take the EC. However, for policy-making the adjustment path is often as important as the eventual goal. Recent work on trade adjustment 
suggests that the presence of in-country sunk costs imply non-standard dynamics.

Specifically, in the presence of such costs, trade flows and prices are subject to hysteresis (see Baldwin [1986 and 1988], Baldwin and Krugman [1988], Dixit [1978a and 1987b]). Again the Harris-Cox simulation approach may prove to be the only way to get a handle on the dynamics of adjustment. 


\section{FOOOIMTIES}

1. For example, see an interview with France's Minister for Industry, Alain Madelin, New York Times, page D1, March 14, 1998.

2. Spence [1976], Dixit and Stiglitz [1977].

\section{FEFERENES}

Baldwin, Richard, "Hysteresis in Trade," MIT mimeo, July 1986. - "Hvsteresis in Import Prices: The Beachhead Effect", American

Economic Review, forthcoming, NBEP, Working Paper, 1988. - and Krugman. Paul, "Persistent Trade Effects of Large Exchange Rate

Shocks," NBER working Paper 2017, September 1986, revised March 1988.

Bhagwati, Jagdish, "Structural Adjustment and International Factor Mobility:

Some Issues." Columbia University Discussion Paper 163, 1982.

Blair, P. and Kaserman, D. Law and Economics of Vertical Integration and

Control, Academic Press, New York, 1983.

Brander, Jim, and Spencer, Barabara, "Tariffs and the Extraction of Foreign

Monopoly Rents under Potential Entry", Canadian Journal of Economics, $371-89.1981$

Dixit, Avinash, "Hysteresis, Import Penetration, and Exchange Rate

Pass-Through," Princeton mimeo, November, $1987 \mathrm{~b}$.

, "Entry and Exit Decisions of Firms under Fluctuating

Real Exchange Rates," Princeton mimeo, October, 1987a.

- and Stiglitz, J. "Monopolistic Competition and Optimum Product

Diversity," American Economic Reveiw 67, 297-308, 1977.

Harris, R. and $\mathrm{Cox}, \mathrm{D}$. Trade, Industrial Policy, and Canadian Manufacturing

Dntario Economic Council, Toronto, Canada, 1982. 
Helleiner, G., Intra-firm Trade and the Developing Countries, St. Martin's Press, NY, 1981.

Helpman, E. and Krugman, P., Market Structure and Foreign Trade, MIT Press, Cambridge, MA, 1985.

Krishna, Kala, "Trade Restrictions as Facilitating Practices," NGER Working Paper, 1546.

Krugman, Paul, "Scale Economies, Product Differentiation, and the Pattern of Trade," American Econonic Feview 70 , 950-959, 1980.

Jones, R., "International Capital Mevements and the Theory of Tariffs", Quarterly Journal of Economics 81, 395-410, 1967.

Munde11, R. "International Trade and Factor Mobility," American Ecomomics Review, $47,321-335,1957$.

Klein. B., Crawford, R. and Alchian, A., "Vertical Integration, Appropriable Rents, and the Competitive Contracting Process," Journa! of Law and Economics 21, 297-326, 1982.

Spence, M. "Product Selection, Fixed Costs, and Monopolistic Competition," Review of Economic Studies $43,217-236,1976$. 